\title{
Overexpression of salusin- $\beta$ is associated with poor prognosis in ovarian cancer
}

\author{
QIAN ZHANG ${ }^{1}$, WEN-MING CHEN ${ }^{2}$, XIN-XIN ZHANG ${ }^{2}$, HU-XIANG ZHANG $^{3}$, \\ HAN-CHU WANG ${ }^{1}$, FEI-YUN ZHENG ${ }^{1}$ and FANG-FANG ZHU ${ }^{1}$ \\ Departments of ${ }^{1}$ Gynecology, ${ }^{2}$ Obstetrics and Gynecology, and ${ }^{3}$ Pathology, \\ The First Affiliated Hospital of Wenzhou Medical University, Wenzhou, Zhejiang 325000, P.R. China
}

Received August 28, 2016; Accepted January 16, 2017

DOI: $10.3892 /$ or.2017.5429

\begin{abstract}
Ovarian cancer is recognized as one of the worst gynecologic malignancies associated with rapid metastasis and poor overall survival rate. The identified valuable molecular biomarkers criticize importance of timely diagnosis for ovarian cancer. Salusin- $\beta$ levels are dramatically increased in women with polycystic ovarian syndrome. However, the roles of salusin- $\beta$ in ovarian cancer have yet to be fully elucidated. A total of 57 paired ovarian cancer specimens and matched adjacent normal tissues were used to measure the salusin- $\beta$ levels. The prognostic value of salusin- $\beta$ for tumor progression and survival rate was investigated. The effects of salusin- $\beta$ on ovarian cancer cell proliferation and epithelial-mesenchymal transition were also explored. The expression of salusin- $\beta$ was significantly increased in ovarian cancer tissue specimens compared with matched normal adjacent tissue $(\mathrm{P}<0.05)$. The high salusin- $\beta$ level was closely related with FIGO stage and lymph node metastases. The ovarian cancer patients with high salusin- $\beta$ had a shorter overall survival $(\mathrm{P}<0.05)$. Salusin- $\beta$ obviously enhanced the proliferation and epithelial mesenchymal-transition of SKOV3 cells. Furthermore, salusin- $\beta$ substantially decreased the expression of p-GSK-3 $\beta$ and GSK-3 $\beta$, but stimulated the $\beta$-catenin expression and downstream genes of wnt $/ \beta$-catenin including cyclin D1 and $\mathrm{C}$-myc. Our data demonstrated for the first time that upregulated salusin- $\beta$ may be a novel independent prognostic biomarker for overall survival of ovarian cancer. Salusin- $\beta$ accelerated the proliferation and epithelial mesenchymal transition of ovarian cancer cells at least partly via activation of $\mathrm{Wnt} / \beta$-catenin signaling pathway. Salusin- $\beta$ may be an important target for therapeutic intervention in ovarian cancer.
\end{abstract}

Correspondence to: Dr Fang-Fang Zhu, Department of Gynaecology, The First Affiliated Hospital of Wenzhou Medical University, 1 Fuxue Lane, Lucheng, Wenzhou, Zhejiang 325000, P.R. China

E-mail: fangfangzhuawz@aliyun.com

Key words: ovarian cancer, salusin- $\beta$, overall survival, proliferation, epithelial-mesenchymal transition

\section{Introduction}

Cancer is known to be a key contributor to mortality around the world, of which ovarian cancer is recognized as one of the most prevalent malignancies among women and is ranking the fifth leading cause of cancer death in women $(1,2)$. The histologic subtypes of ovarian cancer are composed of clear cell, endometrioid, and mucinous adenocarcinomas and serous carcinoma (3). Surgery and chemoradiotherapy are mostly developed for the treatment of ovarian cancer, and had improved the quality of life in patients with ovarian cancer, but the clinical prognosis in these patients is still poor (4). It is reported that a 5-year survival rate is $93 \%$ in patients with ovarian cancer patients at stage I, but only $25 \%$ at the stage IV due to the high recurrence rate, strong metastatic capacity and deficiency of specific symptoms (5). Most of ovarian carcinoma patients are commonly diagnosed at stage III or IV, only $15 \%$ of ovarian cancer patients are diagnosed at early stage (6). Transvaginal ultrasound, manual pelvic examination, and measurement of cancer antigen (CA)-125 are primary tools for the screening of ovarian cancer, but these methods have lowe specificity and sensitivity (7). It has been verified that pathological grade, histological subtype and cancer stage may be critical prognostic factors for ovarian cancer (8). The development of ovarian cancer may be strongly associated with many molecular signals, the ideal molecular biomarkers may be useful for predication of early diagnosis and prognosis of ovarian cancer.

Salusins are bioactive peptides originally identified by bioinformatic analysis of full-length complementary DNA library (9). Salusins are divided into two related bioactive peptides of 28 and 20 amino acids designated salusin- $\alpha$ and salusin- $\beta$. It has been demonstrated that salusins exist in human plasma and vascular system (10). Salusin- $\beta$ is a novel modulator of systemic hemodynamics. It may be critical for aggravation of inflammation and oxidative stress in vasculature (11). Inflammation and oxidative stress are strongly involved in the development of ovarian cancer (12). Moreover, women with polycystic ovarian syndrome have higher salusin- $\beta$ in comparison with the control group (13). It has been confirmed that plasma salusin- $\beta$ level is upregulated in patients with endometrioma and positively associated with endometrioma size (14). Existing evidence suggests that salusin- $\beta$ may play 
Table I. Correlation of salusin- $\beta$ expression with the patient clinicopathological features.

\begin{tabular}{|c|c|c|c|c|c|}
\hline \multirow[b]{2}{*}{ Variables } & \multirow[b]{2}{*}{ All cases $(\%)$} & \multicolumn{2}{|c|}{ Salusin- $\beta$ expression } & \multirow[b]{2}{*}{$\chi^{2}$} & \multirow[b]{2}{*}{ P-value } \\
\hline & & Low $(\%)$ & $\operatorname{High}(\%)$ & & \\
\hline \multicolumn{6}{|l|}{ Age (years) } \\
\hline$\leq 60$ & $35(61.4)$ & $18(51.4)$ & $17(48.6)$ & 0.193 & 0.661 \\
\hline$>60$ & $22(38.6)$ & $10(45.5)$ & $12(54.5)$ & & \\
\hline \multicolumn{6}{|c|}{ Pathological grade } \\
\hline $\mathrm{G} 1+\mathrm{G} 2$ & $38(66.7)$ & $18(47.4)$ & $20(52.6)$ & 0.141 & 0.707 \\
\hline G3 & $19(33.3)$ & $8(42.1)$ & $11(57.9)$ & & \\
\hline \multicolumn{6}{|l|}{ FIGO stage } \\
\hline I + II & $21(36.8)$ & $16(76.2)$ & $5(23.8)$ & 7.402 & 0.007 \\
\hline III + IV & $36(63.2)$ & $14(38.9)$ & $22(61.1)$ & & \\
\hline \multicolumn{6}{|l|}{ Tumor size (cm) } \\
\hline$\leq 2$ & $37(64.9)$ & $20(54.1)$ & $17(45.9)$ & 1.891 & 0.169 \\
\hline$>2$ & $20(35.1)$ & $7(35.0)$ & $13(65.0)$ & & \\
\hline \multicolumn{6}{|c|}{ Histological type } \\
\hline Serous & $25(43.9)$ & $11(44.0)$ & $14(56.0)$ & 0.189 & 0.979 \\
\hline Endometrioid & $14(24.6)$ & $6(42.9)$ & $8(57.1)$ & & \\
\hline Mucinous & $8(14.0)$ & $4(50.0)$ & $4(50.0)$ & & \\
\hline Clear cell & $10(17.5)$ & $4(40.0)$ & $6(60.0)$ & & \\
\hline \multicolumn{6}{|c|}{ Lymph node involvement } \\
\hline Negative & $21 \mathrm{v}(36.8)$ & $14(66.7)$ & $7(33.3)$ & 9.567 & 0.002 \\
\hline Positive & $36(63.2)$ & $9(25.0)$ & $27(75.0)$ & & \\
\hline \multicolumn{6}{|c|}{ Serum CA125 level (U/l) } \\
\hline$\leq 900$ & $26(45.6)$ & $16(61.5)$ & $10(38.5)$ & 1.521 & 0.217 \\
\hline$>900$ & $31(54.4)$ & $14(45.2)$ & $17(54.8)$ & & \\
\hline
\end{tabular}

FIGO, Federation of Gynecology and Obstetrics.

an important role in the reproductive system. However, the roles of salusin- $\beta$ in tumorigenesis, metastasis, and the prognostic significance of ovarian cancer has not yet been clearly established.

\section{Patients and methods}

Patients and specimens. The present study was reviewed and approved by the Research Ethics Committee of the First Affiliated Hospital of Wenzhou Medical University. All experiments were conformed to the Code of Ethics of the World Medical Association (Declaration of Helsinki). A signed written informed consent was provided by the patients. A total of 57 ovarian cancer patients who underwent a curative resection were included from the Department of Gynaecology, the First Affiliated Hospital of Wenzhou Medical University from February 2005 to May 2009. The diagnosis of ovarian cancer was based on the clinical presentations, immunohistochemical staining and morphological criteria. The patients who had history of radiation, chemoradiation, or hormonal therapy were excluded from this study. Fifty-seven cases with ovarian cancer were enrolled in accordance with the inclusion and exclusion criteria. The clinicopathological and demographic data pre- and post-operation were preserved in medical records. The characteristics of patients including age, tumor grade, Federation of Gynecology and Obstetrics (FIGO) stage, histological subtype, tumor size, serum CA-125 level and lymphatic invasion were summarized in Table I. The survival information of each patient was collected by letter, e-mail or phone calls. The overall survival time was considered as the time from the date of surgery to the date of death or the date of last follow-up. The paired tumor tissues and adjacent normal ovarian tissues were immediately frozen in liquid nitrogen and kept at $-80^{\circ} \mathrm{C}$ prior to use.

RNA isolation and quantitative real-time PCR. Total RNA in each sample was isolated from frozen specimen by the TRIzol (Invitrogen, Carlsbad, CA, USA) protocol according to the manufacturer's instructions (15). The concentration and purity of RNA was determined by measuring the absorbance at 260 and $280 \mathrm{~nm}$ with the aid of NanoDrop 1000 spectrophotometer (Thermo Fisher Scientific, Wilmington, DE, USA). The reverse transcription of RNA was then performed using the PrimeScript RT-PCR kit (Takara, Shiga, Japan). The quantitative real-time polymerase chain reaction (RT-PCR) was performed using the SYBR Premix Ex Taq ${ }^{\mathrm{TM}}$ (Takara) on ABI 
7500 Real-Time PCR system (Applied Biosystems, Foster City, CA, USA). The relative proportion of target gene expression was quantified by normalizing the targeted gene level to that of internal control by the $\Delta \Delta \mathrm{Ct}$ method. Primer sequences used are as follows: salusin- $\beta$ : forward, 5'-GAACTTCCACCAA GGGTTCTG-3' and reverse, 5'-GTAAAACGACGGCCAGT AGGAGCGTCGGGAGTTGTAG-3'; glyceraldehyde-3-phosphate dehydrogenase (GAPDH): forward, 5'-GCTCTCTGC TCCTCCTGTTC-3' and reverse, 5'-ACGACCAAATCCGTTG ACTC-3'.

Enzyme linked immunosorbent assay (ELISA) for salusin- $\beta$. The frozen paired ovarian tissues and adjacent normal ovarian tissues were homogenized and centrifuged in lysis buffer. Total protein concentration in the homogenate was measured with the Bradford assay (BCA; Pierce, Santa Cruz, CA, USA). The level of salusin- $\beta$ was assayed by using a commercially available ELISA kit (USCN Life Science, Inc., Houston, TX, USA) according to the manufacturer's protocols as previously reported (15). The values were averaged and expressed as mean picograms per minute per milligram of protein.

Cell culture. The ovarian cancer cell lines including A2780, IGROV1, SKOV3 and OVCAR3 and a control human ovarian surface epithelial cell line (HOSE 6.3) were purchased from the Cell Bank of Chinese Academy of Sciences (Shanghai, China). OVCAR-8 and SKOV-3 were cultured in Dulbecco's modified Eagle's medium (DMEM), and A2780 and IGROV-1 were cultured in RPMI-1640 medium, supplemented with $10 \%$ fetal bovine serum (FBS; Gibco, Grand Island, NY, USA) coupled with $100 \mathrm{U} / \mathrm{ml}$ penicillin sodium, and $100 \mathrm{mg} / \mathrm{ml}$ streptomycin sulfate at $37^{\circ} \mathrm{C}$ in a humidified incubator with $5 \% \mathrm{CO}_{2}$. HOSE 6.3 cells were cultured in MCDB Medium supplemented with $10 \%$ FBS. In addition, SKOV3 cells were incubated with different dose of salusin- $\beta$ at the indicated time, the proliferation and epithelial mesenchymal transition of SKOV3 cells, and the possible signaling pathways in response to salusin- $\beta$ were investigated.

Cell proliferation assay. SKOV3 cell proliferation was assessed with the Cell Counting kit-8 (CCK-8) assay (Dojindo Molecular Technologies, Inc., Kumamoto, Japan) in accordance with the manufacturer's suggestions. Cells were seeded at an initial density of $2 \times 10^{4}$ cells $/ \mathrm{ml}$ in 96 -well plates. The OD450 absorbance was determined to measure cell viability (16). Furthermore, the cell proliferation markers proliferating cell nuclear antigen (PCNA) and phosphorylated histone $\mathrm{H} 3(\mathrm{P}-\mathrm{H} 3)$ were also detected.

Western blot analysis. The cell lysates were collected by using radioimmunoprecipitation assay (RIPA) buffer (Beyotime Institute of Biotechnology, Haimen, China). The total protein concentration in the supernatant was quantified with the Bradford assay (BCA; Pierce). Total cellular proteins were loaded to sodium dodecyl sulfate-polyacrylamide gel electrophoresis (Bio-Rad Laboratories, Inc., Hercules, CA, USA) and transferred to immobilon polyvinylidene difluoride (PVDF) membranes (Millipore, Billerica, MA, USA). The membranes were blocked with 5\% non-fat milk at room temperature and incubated with designed primary antibodies overnight at $4^{\circ} \mathrm{C}$.
The positive signals from HRP-coupled secondary antibodies (Pierce) were visualized. The densitometric analysis of the band intensities was measured and normalized to the band intensities of GAPDH using ImageJ software (NIH, Bethesda, MD, USA). The primary antibodies against proliferating cell nuclear antigen (PCNA), phosphorylated histone H3 (P-H3) and GAPDH were obtained from Santa Cruz Biotechnology (Santa Cruz, CA, USA). N-cadherin, vimentin, GSK-3 $\beta$, p-GSK-3 $\beta$, Snail cyclin D1 and C-myc antibodies were purchased from Cell Signaling Technology, Inc. (Beverly, MA, USA) (17).

Statistical analysis. Data on continuous variables are presented as means \pm standard deviation (SD), and the categorical data are expressed as the percentage. SPSS 19.0 software (SPSS, Inc., Chicago, IL, USA) was used for statistical analysis. The Chi-square or Fisher's exact tests, or t-test were used to evaluate the relationship between the expression of salusin- $\beta$ and other clinical parameters. One-way or two-way ANOVA followed by post hoc Bonferroni test was used when multiple comparisons were made. Survival analysis was estimated with the Kaplan-Meier method. Differences between survival curves were analyzed using the log-rank test. The Cox proportional hazards model was applied for the multivariate survival analysis. The diagnostic efficacy of salusin- $\beta$ was evaluated by receiver operating characteristic (ROC) curve. A two-sided P-value of $<0.05$ was considered statistically significant.

\section{Results}

Overexpression of salusin- $\beta$ expression in prostate cancer tissues. We determined salusin- $\beta$ level in 57 ovarian cancer tissues and matched normal adjacent tissue specimens. RT-PCR results showed that salusin- $\beta$ mRNA level was significantly higher in ovarian cancer tissues than paired adjacent tissue specimens (Fig. 1A). The expression of salusin- $\beta$ at the protein level was obviously upregulated in the ovarian cancer tissues (Fig. 1B). In addition, the levels of salusin- $\beta$ mRNA were dramatically increased in ovarian cancer cell lines including SKOV3, IGROV1, A2780 and OVCAR3 in comparison with normal human ovarian surface epithelial HOSE 6.3 cells (Fig. 1C). As the SKOV3 cell line exhibited the highest salusin- $\beta$ mRNA level, the SKOV3 cell line was selected for the in vitro experiments.

Diagnostic efficacy of miR-129 in prostate cancer patients. The assessment of diagnostic efficacy of salusin- $\beta$ in ovarian cancer patients was performed by calculating the area under the receiver operating characteristic curve. The ROC curve analysis revealed that AUC was $0.154(\mathrm{P}=0.026)$. At the cut-off value 339.8 , the diagnostic sensitivity $(70.2 \%)$ and specificity $(89.4 \%)$ reached their peak values $(\mathrm{P}<0.05$; Fig. 2$)$. Thus, the salusin- $\beta$ expression was further classified into the low expression group ( $\mathrm{n}=$ salusin $-\beta$ expression $<339.8, \mathrm{n}=32$ ) and high expression group (salusin- $\beta$ expression $\geq 339.8, \mathrm{n}=25$ ) as the threshold ROC curve value of 339.8 (Fig. 2A).

Correlation of salusin- $\beta$ expression with clinical parameters of ovarian cancer patients. As shown in Table I, the high 

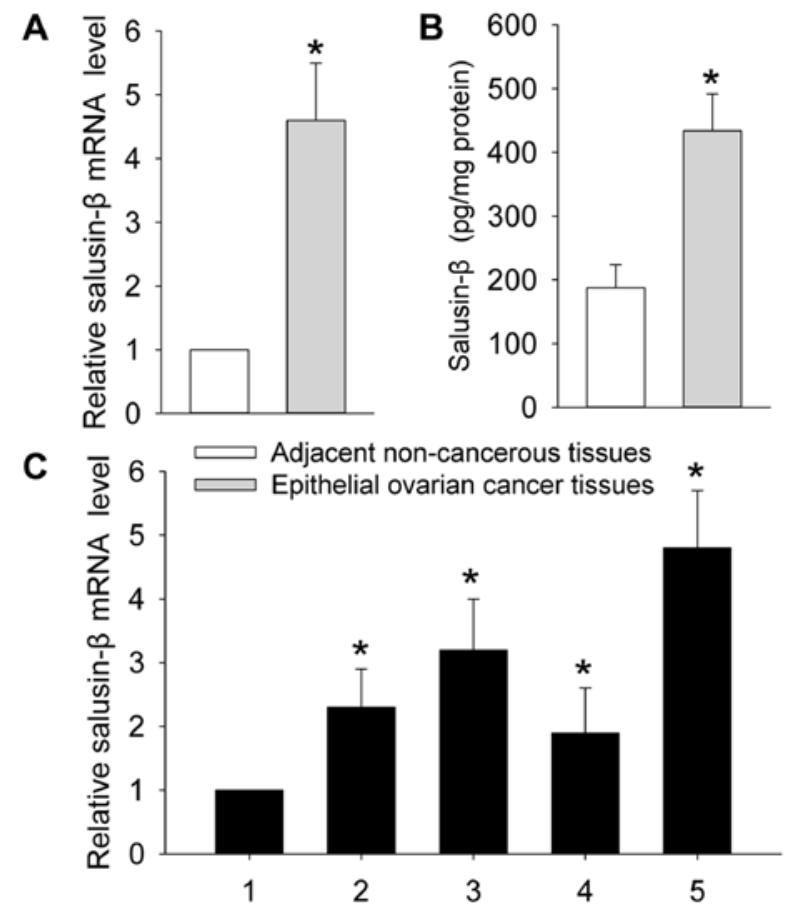

Figure 1. Expressions of salusin- $\beta$ in paired adjacent non-cancerous tissues and epithelial ovarian cancer tissues detected by real-time quantitative RT-PCR assay (A) or enzyme linked immunosorbent assay (ELISA) kit (B). (C) Higher expression levels of salusin- $\beta$ were detected in 4 ovarian cancer cell lines (2, A2780), (3, OVCAR3), (4, IGROV1), (5, SKOV3), compared with values obtained for the normal human ovarian surface epithelial cell line (1, HOSE 6.3) determined with RT-PCR. The results showed that salusin- $\beta$ expression level was significantly increased in epithelial ovarian cancer tissues and cell lines. ${ }^{*} \mathrm{P}<0.05$ vs. adjacent non-cancerous tissues or 1 , HOSE 6.3. Values are mean $\pm \mathrm{SD}$. ${ }^{*} \mathrm{P}<0.05$ vs. control.

salusin- $\beta$ expression is closely associated with the FIGO stage $(\mathrm{P}=0.007)$ and lymph node involvement $(\mathrm{P}=0.002)$ in ovarian cancer patients. However, we found no significant correlations between salusin- $\beta$ expression and age $(\mathrm{P}=0.661)$, pathological grade $(\mathrm{P}=0.707)$, tumor size $(\mathrm{P}=0.169)$, histological type $(\mathrm{P}=0.979)$ or serum $\mathrm{CA} 125$ level $(\mathrm{P}=0.217)$ in patients with ovarian cancer.

Relationship between salusin- $\beta$ expression and overall survival. The possible prognostic value of salusin- $\beta$ in overall survival in patients with ovarian cancer was performed by calculating the cumulative survival curves with the KaplanMeier method. The Kaplan-Meier curves between high or low salusin- $\beta$ expression and overall survival demonstrated that the ovarian cancer patients with high salusin- $\beta$ expression had an obviously shorter overall survival $(\mathrm{P}=0.000$; Fig. 2B). Multivariate Cox proportional hazards regression analysis revealed that FIGO stage, lymph node involvement, salusin- $\beta$ expression were closely related with overall survival rate in ovarian cancer patients, and these parameters may be employed as independent prognostic indicators for overall survival of ovarian cancer patients $(\mathrm{P}<0.05$; Table II).

Salusin- $\beta$ promotes the proliferation of SKOV3 cells. The excessive proliferation of cancer cells is critical for the development and progression of ovarian cancer patients (18). The SKOV 3 cells were challenged by salusin- $\beta$ in the dedicated
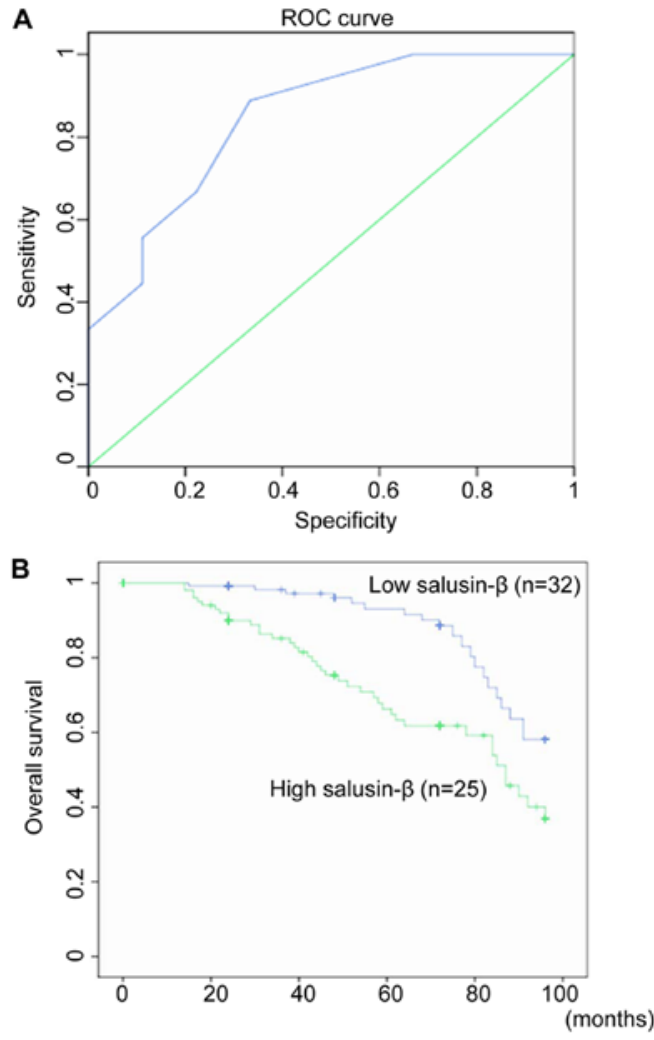

Figure 2. ROC curve and Kaplan-Meier survival analysis of salusin- $\beta$ in epithelial ovarian cancer patients. (A) Assessment of the diagnostic efficacy of salusin- $\beta$ in epithelial ovarian cancer tissues of patients by calculating the area under the receiver operating characteristic curve. ( $\mathrm{AUC}=0.154$, $\mathrm{P}=0.026$, sensitivity $=0.702$; specificity $=0.894$ ). (B) Kaplan-Meier survival analysis stratified according to salusin- $\beta$ expression in epithelial ovarian cancer patients. The patients with higher salusin- $\beta$ expression had significantly shorter overall survival than patients with lower salusin- $\beta$ expression $(\mathrm{P}<0.001)$.
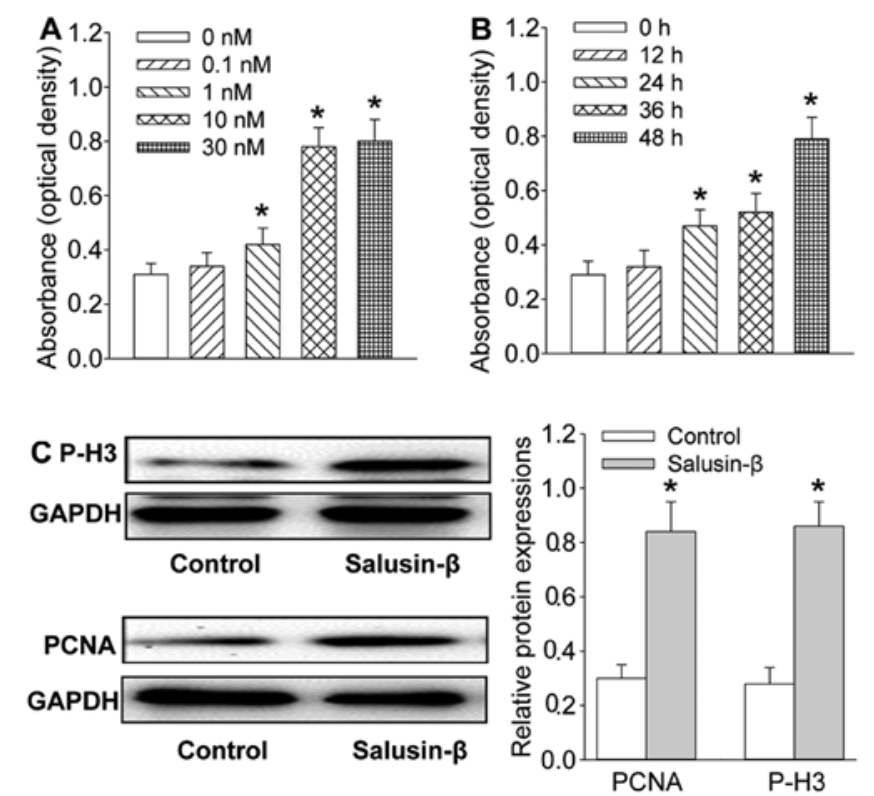

Figure 3. Effects of salusin- $\beta$ on SKOV3 cell proliferation. (A) Effects of different concentration of salusin- $\beta(0.01,0.1,1,10$ and $300 \mathrm{nM})$ for $48 \mathrm{~h}$ on SKOV3 proliferation determined with CCK-8 kits; (B) effects of salusin- $\beta$ $(10 \mathrm{nM})$ treated for $0,12,24,36$ and $48 \mathrm{~h}$ on SKOV3 proliferation determined with CCK- 8 kits; (C) effect of salusin- $\beta$ on the proliferating cell nuclear antigen (PCNA) and phosphorylated histone $\mathrm{H} 3$ (P-H3) levels (markers of proliferation) in SKOV3 cells. Values are mean $\pm \mathrm{SD}$. ${ }^{*} \mathrm{P}<0.05$ vs. control. 
Table II. Cox multivariate analysis of the clinicopathological parameters for overall survival.

\begin{tabular}{|c|c|c|c|}
\hline Variables & Hazard ratio & $95 \% \mathrm{CI}$ & P-value \\
\hline Age ( $\leq 60$ vs. $>60$ years $)$ & 1.271 & $0.436-3.702$ & 0.868 \\
\hline Pathological grade (G1 + G2 vs. G3) & 1.238 & $0.407-3.760$ & 0.926 \\
\hline FIGO stage (I + II vs. III + IV) & 5.029 & $1.504-16.816$ & 0.015 \\
\hline Tumor size $(\leq 2$ vs. $>2 \mathrm{~cm})$ & 2.185 & $0.710-6.720$ & 0.277 \\
\hline Serum CA125 ( $\leq 900$ vs. >900 U/l) & 1.943 & $0.673-5.610$ & 0.338 \\
\hline Lymph node involvement (negative vs. positive) & 7.286 & $2.286-23.223$ & 0.001 \\
\hline Salusin- $\beta$ expression (high vs. low) & 4.675 & $1.518-14.395$ & 0.006 \\
\hline
\end{tabular}

CI, confidence interval.

A
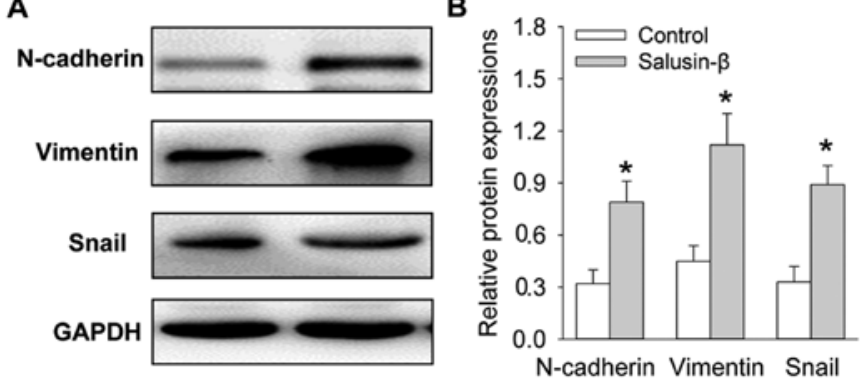

Figure 4. Salusin- $\beta$ promotes epithelial-mesenchymal transition of SKOV3 cells. (A) Western blot analysis of $\mathrm{N}$-cadherin ( $\mathrm{N}-\mathrm{cad})$, vimentin, Snail and $\beta$-actin in SKOV3 cells $48 \mathrm{~h}$ after incubation with salusin- $\beta(10 \mathrm{nM})$ or control. (B) Measurement of the relative gray scale of $\mathrm{N}$-cad, vimentin and Snail vs. $\beta$-actin. Values are mean \pm SD. ${ }^{*} \mathrm{P}<0.05$ vs. control. $\mathrm{n}=6$ for each group.

time and concentration for evaluation of the effect of salusin- $\beta$ on the proliferation of ovarian cancer cell with CCK8 assay in vitro. Salusin- $\beta$ stimulated the SKOV3 cell proliferation in a time-dependent manner (Fig. 3A) and dose-related fashion (Fig. 3B). Furthermore, the proliferating markers including PCNA and phosphorylated histone H3 (P-H3) were also obviously increased in SKOV3 cells in response to salusin- $\beta$ incubation at dose of $10 \mathrm{nM}$ for $48 \mathrm{~h}$ (Fig. 3C).

Salusin- $\beta$ stimulated the epithelial mesenchymal transition of SKOV3 cells. Epithelial mesenchymal transition is a key event in the acceleration of migration and invasion of cancer cells (19). Western blot analysis illustrated that salusin- $\beta$ significantly upregulated the protein expressions of mesenchymal markers including N-cadherin, vimentin and Snail in SKOV3 cells (Fig. 4).

Salusin- $\beta$ modulated Wnt/ $\beta$-catenin signaling pathway in SKOV3 cells. Wnt/ $\beta$-catenin signaling pathway is one of the crucial pathways, and majorly contributes to the proliferation and EMT and epithelial mesenchymal transition in ovarian cancer $(20,21)$. Incubation of SKOV3 cells with salusin- $\beta$ substantially inhibited expressions of p-GSK-3 $\beta$ and GSK-3 $\beta$, and remarkably augmented the $\beta$-catenin levels and increased the transcription of the targeted genes of Wnt/ $\beta$-catenin, such as cyclin D1 and C-myc (Fig. 5).

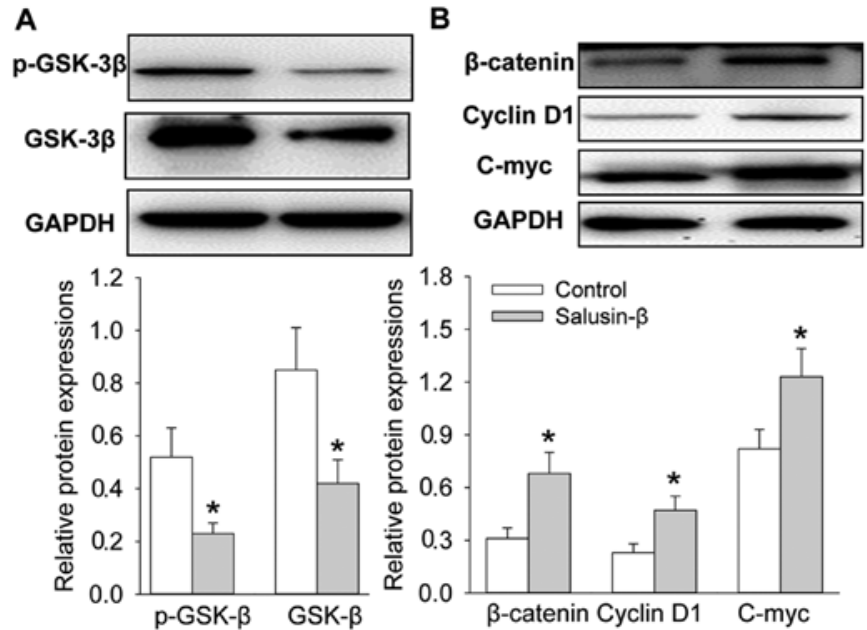

Figure 5. Salusin- $\beta$ stimulates $\mathrm{Wnt} / \beta$-catenin signaling pathway in SKOV3 cells. (A) Western blot analysis of p-GSK-3 $\beta$, GSK-3 $\beta$ in SKOV3 cells $48 \mathrm{~h}$ after incubation with salusin- $\beta(10 \mathrm{nM})$ or control. (B) Western blot analysis of $\beta$-catenin, cyclin D1 and C-myc in SKOV3 cells $48 \mathrm{~h}$ after incubation with salusin- $\beta$ or control. Values are mean \pm SD. ${ }^{*} \mathrm{P}<0.05$ vs. control. $\mathrm{n}=6$ for each group.

\section{Discussion}

Ovarian cancer patients suffer from high disease recurrence and mortality (1). Early diagnosis and treatment may be helpful for prevention of progression of ovarian cancer (4). The absence of useful biomarkers has disappointed the clinical outcome of ovarian cancer therapy. It has been disclosed that various molecules are identified to be biomarkers for prognosis in cancer. The utility of novel biomarkers may provide a better understanding of cancer biological behavior, thus, useful biomarkers for cancer are continuously characterized in recent years (2). The present study established an intimate relationship of salusin- $\beta$ with aggressive clinicopathological parameters including FIGO stage and lymph node involvement in ovarian cancer patients. Salusin- $\beta$ may be a crucial component in the pathogenesis of ovarian cancer associated with the deteriorated proliferation and epithelial-mesenchymal transition of ovarian cancer cells via modulation of $\mathrm{Wnt} / \beta$-catenin signaling pathway.

Deficiency of diagnostic and prognostic factors may be largely responsible for the poor outcome of ovarian cancer. 
It has been recommended that early and accurate diagnosis of ovarian cancer is beneficial for the appropriate therapy. It was recently reported that the microRNA (miRNA) miR-498 is significantly decreased in ovarian cancer tissues, and may be taken as a valuable factor in predicting the prognosis in patients with ovarian cancer (22). It is also demonstrated that downregulated miR-22 was closely related with the overall survival of epithelial ovarian cancer, and is an efficient prognostic factor for patients with epithelial ovarian cancer (23). The secretory small guanosine 5'-triphosphate binding enzyme, Rab27B was also recently identified to be an independent prognostic factor for the survival of ovarian cancer patients (24). Salusin- $\beta$ is a bioactive peptide with hypotensive and bradycardiac effects (25). Salusin- $\beta$ is found to accelerate inflammation responses, oxidative stress and tube formation in human in human endothelial cells, and promotes monocyte-endothelial adhesion (26). Salusin- $\beta$ is a stimulator for the migration of vascular smooth muscle cells (VSMCs) with regard to vascular injury (15). Salusin- $\beta$ may be used as a biomarker for atherosclerotic cardiovascular diseases (27). The serum salusin- $\beta$ level is increased in patients with endometrioma and positively associated with endometrioma size (14). A series of studies in salusin- $\beta$ led us to explore whether or how salusin- $\beta$ affected the progression of ovarian cancer. In this study, we showed that the ovarian cancer tissues exhibited an obvious increase in salusin- $\beta$ expression. The upregulation of salusin- $\beta$ was positively associated with the FIGO stage and lymph node metastasis in ovarian cancer patients. The ovarian cancer patients with high expression of salusin- $\beta$ had shorter overall survival. Multivariate analyses further proved that salusin- $\beta$ was a potential independent prognostic factor for overall survival of patients with ovarian cancer. To the best of our knowledge, our results are the first identifying the prognostic significance of salusin- $\beta$ in ovarian cancer. These results hinted that salusin- $\beta$ may be a new prognostic biomarker for ovarian cancer.

The abnormal growth of cancer cells is one of the most important events in tumorigenesis and tumor progression $(28,29)$. Salusin- $\beta$ induces potent mitogenic effects on human VSMCs and fibroblasts (9). In the present study, we showed that salusin- $\beta$ stimulated the SKOV3 cell proliferation time- and dose-dependently. Furthermore, the proliferating markers including PCNA and phosphorylated histone H3 (P-H3) were also obviously increased in SKOV3 cells in response to salusin- $\beta$. These results suggested that salusin- $\beta$ may function as an accelerator in the proliferation of ovarian cancer cells.

Epithelial mesenchymal transition is defined as a process of cell remodeling in embryonic development and organogenesis, and it functionally contributes to malignant tumor progression (30). N-cadherin, vimentin and Snail are key components in the process of epithelial-mesenchymal transition (31). Herein, we showed that salusin- $\beta$ significantly upregulated the protein expression of mesenchymal markers including $\mathrm{N}$-cadherin, vimentin and Snail in SKOV3 cells. These results indicated that salusin- $\beta$ may be a new player in the regulation of epithelial-mesenchymal transition for ovarian cancer metastasis.

$\mathrm{Wnt} / \beta$-catenin pathway is essential for the proliferation and epithelial-mesenchymal transition in ovarian cancer (32).
Activation of $\mathrm{Wnt} / \beta$-catenin pathway is known to promote the proliferation, epithelial-mesenchymal transition of ovarian cancer cells $(33,34)$. Application of the $\mathrm{Wnt} / \beta$-catenin pathway inhibitor WNT974, induces cell cycle arrest and inhibits the proliferation of primary ovarian cancer cells (35). Cyclin Y exerts promotion on the proliferation, migration, and invasion of ovarian cancer cells associated with increased expression of $\mathrm{C}$-myc, cyclin D1 and $\beta$-catenin protein (36). In vitro studies demonstrate cyclin G2 retards ovarian cancer cell proliferation, migration, invasion and epithelial-mesenchymal transition through disruption of Wnt/ $\beta$-catenin pathway (37). In the present study, we displayed that incubation of SKOV3 cells with salusin- $\beta$ substantially inhibited expression of p-GSK-3 $\beta$ and GSK-3 $\beta$, and remarkably augmented the $\beta$-catenin levels and increased the transcription of the targeted genes of Wnt/ $\beta$-catenin, such as cyclin D1 and C-myc. These results implied that salusin- $\beta$ may activate the $\mathrm{Wnt} / \beta$-catenin signaling pathway, which may be involved in proliferation and epithelial-mesenchymal transition in ovarian cancer.

Collectively, our results showed that overexpression of salusin- $\beta$ may participate in the progression of ovarian cancer. We also highlighted the potential usefulness of salusin- $\beta$ for prognosis in patients with ovarian cancer. Salusin- $\beta$ may activate the $\mathrm{Wnt} / \beta$-catenin signaling pathway to promote the proliferation and epithelial mesenchymal transition of ovarian cancer cells. Salusin- $\beta$ might be considered as a novel molecular target for the diagnosis and treatment of prostate cancer.

\section{References}

1. Siegel R, Naishadham D and Jemal A: Cancer statistics, 2013. CA Cancer J Clin 63: 11-30, 2013.

2. Jemal A, Bray F, Center MM, Ferlay J, Ward E and Forman D: Global cancer statistics. CA Cancer J Clin 61: 69-90, 2011.

3. $\mathrm{Ma} \mathrm{M}$ and $\mathrm{Yu} \mathrm{N}$ : Ubiquitin-specific protease 7 expression is a prognostic factor in epithelial ovarian cancer and correlates with lymph node metastasis. Onco Targets Ther 9: 1559-1569, 2016.

4. Zhao GY, Lin ZW, Lu CL, Gu J, Yuan YF, Xu FK, Liu RH, Ge D and Ding JY: USP7 overexpression predicts a poor prognosis in lung squamous cell carcinoma and large cell carcinoma. Tumour Biol 36: 1721-1729, 2015.

5. Holschneider CH and Berek JS: Ovarian cancer: Epidemiology, biology, and prognostic factors. Semin Surg Oncol 19: 3-10, 2000.

6. Nathan JA, Sengupta S, Wood SA, Admon A, Markson G, Sanderson C and Lehner PJ: The ubiquitin E3 ligase MARCH7 is differentially regulated by the deubiquitylating enzymes USP7 and USP9X. Traffic 9: 1130-1145, 2008.

7. Jelovac D and Armstrong DK: Recent progress in the diagnosis and treatment of ovarian cancer. CA Cancer J Clin 61: 183-203, 2011.

8. Zhang $\mathrm{X}$ and Zhang H: Diminished miR-613 expression as a novel prognostic biomarker for human ovarian cancer. Eur Rev Med Pharmacol Sci 20: 837-841, 2016.

9. Shichiri M, Ishimaru S, Ota T, Nishikawa T, Isogai $\mathrm{T}$ and Hirata Y: Salusins: Newly identified bioactive peptides with hemodynamic and mitogenic activities. Nat Med 9: 1166-1172, 2003.

10. Celik E, Celik O, Yilmaz E, Turkcuoglu I, Karaer A, Turhan U and Aydin S: Association of low maternal levels of salusins with gestational diabetes mellitus and with small-for-gestational-age fetuses. Eur J Obstet Gynecol Reprod Biol 167: 29-33, 2013.

11. Sato K, Watanabe R, Itoh F, Shichiri M and Watanabe T: Salusins: Potential use as a biomarker for atherosclerotic cardiovascular diseases. Int J Hypertens 2013: 965140, 2013.

12. Olson SH, Carlson MD, Ostrer H, Harlap S, Stone A, Winters M and Ambrosone CB: Genetic variants in SOD2, MPO, and NQO1, and risk of ovarian cancer. Gynecol Oncol 93: 615-620, 2004. 
13. Celik Ö, Y1lmaz E, Celik N, Minareci Y, Turkcuoglu I, Simsek Y, Celik E, Karaer A and Aydin S: Salusins, newly identified regulators of hemodynamics and mitogenesis, increase in polycystic ovarian syndrome. Gynecol Endocrinol 29: 83-86, 2013.

14. Sahin L, Bozkurt M, Celik O, Celik N, Aydin S and Gencdal S: Serum salusins levels are increased and correlated positively with cyst size in ovarian endometrioma. Gynecol Endocrinol 31: 639-642, 2015

15. Sun HJ, Zhao MX, Ren XS, Liu TY, Chen Q, Li YH, Kang YM, Wang JJ and Zhu GQ: Salusin-beta promotes vascular smooth muscle cell migration and intimal hyperplasia after vascular injury via ROS/NFkappaB/MMP-9 pathway. Antioxid Redox Signa 24: 1045-1057, 2016.

16. Sun HJ, Liu TY, Zhang F, Xiong XQ, Wang JJ, Chen Q, Li YH, Kang YM, Zhou YB, Han Y, et al: Salusin- $\beta$ contributes to vascular remodeling associated with hypertension via promoting vascular smooth muscle cell proliferation and vascular fibrosis. Biochim Biophys Acta 1852: 1709-1718, 2015.

17. Sun HJ, Zhang LL, Fan ZD, Chen D, Zhang L, Gao XY, Kang YM and Zhu GQ: Superoxide anions involved in sympathoexcitation and pressor effects of salusin- $\beta$ in paraventricular nucleus in hypertensive rats. Acta Physiol (Oxf) 210: 534-545, 2014.

18. Wang S and Liu W: Paeoniflorin inhibits proliferation and promotes apoptosis of multiple myeloma cells via its effects on microRNA-29b and matrix metalloproteinase-2. Mol Med Rep 14: 2143-2149, 2016.

19. Chen J, Wang S, Su J, Chu G, You H, Chen Z, Sun H, Chen B and Zhou M: Interleukin-32 $\alpha$ inactivates JAK2/STAT3 signaling and reverses interleukin-6-induced epithelial-mesenchymal transition, invasion, and metastasis in pancreatic cancer cells. Onco Targets Ther 9: 4225-4237, 2016.

20. Shan S, Lv Q, Zhao Y, Liu C, Sun Y, Xi K, Xiao J and Li C: $\mathrm{Wnt} / \beta$-catenin pathway is required for epithelial to mesenchymal transition in CXCL12 over expressed breast cancer cells. Int J Clin Exp Pathol 8: 12357-12367, 2015.

21. Xiao C, Wu CH and Hu HZ: LncRNA UCA1 promotes epithelial-mesenchymal transition (EMT) of breast cancer cells via enhancing Wnt/beta-catenin signaling pathway. Eur Rev Med Pharmacol Sci 20: 2819-2824, 2016.

22. Cong J, Liu R, Wang X, Wang J, Wang H and Hou J: Low miR-498 expression levels are associated with poor prognosis in ovarian cancer. Eur Rev Med Pharmacol Sci 19: 4762-4765, 2015.

23. Wan WN, Zhang YQ, Wang XM, Liu YJ, Zhang YX, Que YH, Zhao WJ and Li P: Down-regulated miR-22 as predictive biomarkers for prognosis of epithelial ovarian cancer. Diagn Pathol 9: 178, 2014.

24. Ren P, Yang XQ, Zhai XL, Zhang YQ and Huang JF: Overexpression of Rab27B is correlated with distant metastasis and poor prognosis in ovarian cancer. Oncol Lett 12: 1539-1545, 2016.
25. Niepolski L and Grzegorzewska AE: Salusins and adropin: New peptides potentially involved in lipid metabolism and atherosclerosis. Adv Med Sci 61: 282-287, 2016.

26. Xu T, Zhang Z, Liu T, Zhang W, Liu J, Wang W and Wang J: Salusin- $\beta$ contributes to vascular inflammation associated with pulmonary arterial hypertension in rats. $\mathbf{J}$ Thorac Cardiovasc Surg 152: 1177-1187, 2016.

27. Liu J, Ren YG, Zhang LH, Tong YW and Kang L: Serum salusinbeta levels are associated with the presence and severity of coronary artery disease. J Investig Med 63: 632-635, 2015.

28. Hu X and Sun S: RAD51 Gene 135G/C polymorphism and ovarian cancer risk: A meta-analysis. Int J Clin Exp Med 8: 22365-22370, 2015.

29. Liu X and Li G: MicroRNA-133b inhibits proliferation and invasion of ovarian cancer cells through Akt and Erk1/2 inactivation by targeting epidermal growth factor receptor. Int J Clin Exp Pathol 8: 10605-10614, 2015.

30. Diepenbruck M and Christofori G: Epithelial-mesenchymal transition (EMT) and metastasis: Yes, no, maybe? Curr Opin Cell Biol 43: 7-13, 2016.

31. Xu Q, Deng F, Qin Y, Zhao Z, Wu Z, Xing Z, Ji A and Wang QJ: Long non-coding RNA regulation of epithelial-mesenchymal transition in cancer metastasis. Cell Death Dis 7: e2254, 2016.

32. Kypta RM and Waxman J: Wnt/ $\beta$-catenin signalling in prostate cancer. Nat Rev Urol 9: 418-428, 2012.

33. Yoshida S, Furukawa N, Haruta S, Tanase Y, Kanayama S, Noguchi T, Sakata M, Yamada Y, Oi H and Kobayashi H: Expression profiles of genes involved in poor prognosis of epithelial ovarian carcinoma: a review. Int J Gynecol Cancer 19: 992-997, 2009.

34. Arend RC,Londoño-Joshi AI, Straughn JM Jr and Buchsbaum DJ: The Wnt $/ \beta$-catenin pathway in ovarian cancer: A review. Gynecol Oncol 131: 772-779, 2013.

35. Boone JD, Arend RC, Johnston BE, Cooper SJ, Gilchrist SA, Oelschlager DK, Grizzle WE, McGwin G Jr, Gangrade A, Straughn JM Jr, et al: Targeting the Wnt/ $\beta$-catenin pathway in primary ovarian cancer with the porcupine inhibitor WNT974. Lab Invest 96: 249-259, 2016.

36. Liu H, Shi H, Fan Q and Sun X: Cyclin Y regulates the proliferation, migration, and invasion of ovarian cancer cells via Wnt signaling pathway. Tumour Biol 37: 10161-10175, 2016.

37. Bernaudo S, Salem M, Qi X, Zhou W, Zhang C, Yang W, Rosman D, Deng Z, Ye G, Yang B, et al: Cyclin G2 inhibits epithelial-to-mesenchymal transition by disrupting Wnt/ $\beta$-catenin signaling. Oncogene 35: 4816-4827, 2016 